\title{
Noninvasive estimate of left ventricular filling pressure correlated with early and midterm postoperative cardiovascular events after isolated aortic valve replacement in patients with severe aortic stenosis
}

\author{
Sung-A Chang, MD, ${ }^{\mathrm{a}}$ Pyo-Won Park, MD, ${ }^{\mathrm{b}}$ Kiick Sung, MD, ${ }^{\mathrm{b}}$ Sang-Chol Lee, MD, ${ }^{\mathrm{a}}$ Seung Woo Park, MD, ${ }^{\mathrm{a}}$
} Young Tak Lee, MD, ${ }^{b}$ and Jae K. Oh, MD ${ }^{a, c}$

Objectives: The aim of this study was to investigate whether preoperative estimated left ventricular filling pressure predicts the postoperative outcome in patients with severe aortic stenosis.

\begin{abstract}
Methods: Two hundred ten patients who underwent isolated aortic valve replacement because of severe aortic stenosis were analyzed. Left ventricular filling pressure was noninvasively assessed based on the ratio between early diastolic mitral inflow and mitral annular velocity $\left(\mathrm{E} / \mathrm{E}^{\prime}\right)$, which was calculated based on results of mitral inflow and mitral annular tissue Doppler scanning. Early postoperative hospital events were reviewed. Postoperative mortality and morbidity were searched and compared according to left ventricular filling pressure.
\end{abstract}

\begin{abstract}
Results: Preoperative functional class was associated with increased $\mathrm{E} / \mathrm{E}^{\prime}$ values. Postoperative hospital events were higher in patients with increased preoperative $\mathrm{E} / \mathrm{E}^{\prime}$ values. Midterm mortality of the overall population was very low after aortic valve replacement $(2 \%)$. Cardiovascular event-free survival, including hospital visits caused by heart failure symptoms, embolic cerebral infarction, and sudden cardiac death, was significantly lower in the patients with increased left ventricular filling pressure and $\mathrm{E} / \mathrm{E}^{\prime}$ values of greater than $12(P=.03)$. Multivariable analysis showed a high hazard ratio of increased $\mathrm{E} / \mathrm{E}^{\prime}$ values of greater than 12 (hazard ratio, $41 ; P<.001$ ).
\end{abstract}

Conclusions: The incidence of postoperative mortality after isolated aortic valve replacement caused by severe aortic stenosis is relatively low in the current era. $\mathrm{E} / \mathrm{E}^{\prime}$ representing diastolic filling pressure is the most important preoperative predictor of risk of early postoperative hospital course and postoperative morbidity. (J Thorac Cardiovasc Surg 2010;140:1361-6)

Prolonged pressure overload in patients with severe aortic stenosis (AS) induces remodeling of the left ventricle and alteration of both systolic and diastolic function. As a result, left ventricular (LV) filling pressure is commonly increased in patients with severe AS. ${ }^{1,2}$ The increased filling pressure results in pulmonary hypertension and dyspnea ${ }^{2}$ in this patient population. However, most patients with increased LV filling pressure in the setting of severe AS have a normal left ventricular ejection fraction (LVEF). It is also likely that the increased filling pressure is partly related to superimposed diastolic dysfunction independent of se-

\footnotetext{
From the Cardiovascular Imaging Center, Cardiac and Vascular Center, ${ }^{\mathrm{a}}$ and the Department of Thoracic and Cardiovascular Surgery, ${ }^{\mathrm{b}}$ Samsung Medical Center, Sungkyunkwan University School of Medicine, Seoul, Korea; and the Division of Cardiovascular Diseases, ${ }^{\mathrm{c}}$ Mayo Clinic College of Medicine, Rochester, Minn. Disclosures: None.

Received for publication July 21, 2009; revisions received Jan 12, 2010; accepted for publication Feb 8, 2010; available ahead of print April 12, 2010.

Address for reprints: Jae K. Oh, MD, Division of Cardiovascular Diseases, Mayo Clinic College of Medicine, Gonda 6 South, 200 1st st SW, Rochester, MN 55905 (E-mail: oh.jae@mayo.edu); and Pyo-Won Park, MD, Department of Thoracic and Cardiovascular Surgery, Samsung Medical Center, Sungkyunkwan University School of Medicine, 50 IL Won-Dong, Kangnam-Ku, Seoul, 135-230, South Korea (E-mail: pwpark@skku.edu).

$0022-5223 / \$ 36.00$

Copyright (c) 2010 by The American Association for Thoracic Surgery doi:10.1016/j.jtcvs.2010.02.022
}

vere AS. After aortic valve replacement (AVR), LV afterload rapidly decreases and LV function improves, but LV filling pressure can remain increased in some patients for years after surgical intervention and affects postoperative outcomes. $^{3,4}$

Increased LV filling pressure is associated with diastolic dysfunction and hence is a reliable parameter to evaluate LV diastolic dysfunction. ${ }^{5}$ Previous reports suggested that diastolic dysfunction, ${ }^{6}$ pulmonary hypertension, ${ }^{7}$ and more severe functional class ${ }^{4}$ were associated with poor patient outcomes, and all of these factors can be explained by increased LV filling pressure. Therefore the single parameter of LV filling pressure might predict postoperative outcomes after AVR because of severe AS.

The velocity of mitral annular motion can be easily measured online by using echocardiography with the Doppler tissue-imaging technique. Because early diastolic velocity of the mitral annulus is a relatively load-independent index of LV relaxation and early mitral inflow velocity is associated with relaxation and $\mathrm{LV}$ filling pressure, the simple ratio between early diastolic mitral inflow and mitral annular velocity $\left(E / E^{\prime}\right)$ has been shown to be a reliable method for noninvasive estimation of LV filling pressure. ${ }^{8,9}$ It is now routinely used in clinical practice, including in patients with moderate-to-severe $\mathrm{AS} .{ }^{10}$ The primary aim of this study 


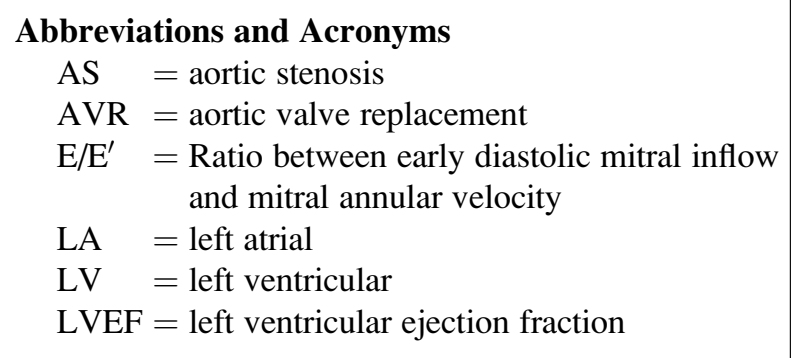

was to investigate whether preoperative $\mathrm{E} / \mathrm{E}^{\prime}$ values (noninvasively estimated LV filling pressure) predict postoperative adverse outcomes in patients with severe AS.

\section{MATERIALS AND METHODS Study Population}

Two hundred forty-eight patients who underwent isolated AVR for degenerative severe AS from January 2003 to December 2008 in Samsung Medical Center were retrospectively reviewed. Patients who had rheumatic AS, other severe valve diseases requiring a valve operation, and a history of previous cardiac surgery or recent myocardial infarction in the last 6 months were excluded from this study. Patients who presented with acute coronary syndrome with left main disease or multivessel disease were also excluded. Of the 248 patients, 210 who had complete preoperative echocardiographic analysis, including tissue Doppler parameters, were our study subjects. Hospital records were reviewed, and clinical variables, including age, sex, cardiovascular risk factors, and/or other variables regarding AVR, were investigated.

\section{Echocardiographic Examination}

Preoperative echocardiographic parameters were acquired from our electronic medical database. Preoperative echocardiographic analysis was usually performed within 2 weeks before the operation. As a routine protocol, our laboratory measures LV systolic and diastolic dimensions, end-diastolic LV wall thickness, LVEF, and pulsed-wave Doppler velocities of mitral inflow. The LV mass index was calculated based on M-mode echocardiographic analysis, as previously described,${ }^{11}$ and the left atrial (LA) volume index was calculated with the prolate-ellipsoid biplane method. ${ }^{12}$ Peak early (E) and late (A) diastolic velocities of mitral inflow were measured by using pulsed-wave Doppler scanning at the tip of the mitral valve leaflets. Peak early $\left(\mathrm{E}^{\prime}\right)$ and late $\left(\mathrm{A}^{\prime}\right)$ diastolic mitral annular velocities were acquired at the septum in the apical 4-chamber view. Aortic valve mean and peak transvalvular gradients were calculated from the peak aortic valve Doppler velocities interrogated from multiple transducer locations. Aortic valve area was calculated by using the continuity equation. ${ }^{13}$

\section{Outcome Measures}

The postoperative hospital course was reviewed regarding in-hospital cardiovascular events. In-hospital complications were divided into surgical and cardiovascular complications. The former included wound problems, including infection or bleeding and redo operations caused by technical failure. Cardiovascular complications were defined as cerebral embolism, cardiopulmonary resuscitation, and arrhythmia requiring cardioversion or pacemaker insertion before discharge. If a cardiovascular complication was associated with a surgical complication, that event was excluded from the cardiovascular events. Early postoperative mortality was defined as death within 30 days after AVR.

Postoperative outcomes and events after discharge were acquired from the review of medical records, direct telephone interviews with patients or their families, and national registry of birth and death data. Cause of death was classified as cardiac (sudden death, heart failure, or myocardial infarction) or noncardiac. Cardiovascular events were defined as heart failure requiring hospital admission or an early hospital visit, embolic cerebral infarction, or cardiac death during the follow-up period. This study protocol for retrospective review and follow-up analysis was approved by our institutional review committee (Samsung Medical Center).

\section{Statistical Analysis}

Continuous variables are expressed as means \pm standard deviations. Time variables were expressed as medians \pm interquartile ranges. Categorical variables are expressed as numbers and percentages. For comparison between 2 groups, the $\chi^{2}$ test or Fisher's exact test was used for categorical variables, and the independent $t$ test or Mann-Whitney test was applied for continuous variables, where appropriate, according to normality. The optimal cutoff value of $\mathrm{E} / \mathrm{E}^{\prime}$ to predict postoperative morbidity was determined by using receiver operating characteristic curve analysis. Postoperative clinical outcomes were demonstrated by using the curve derived from the Kaplan-Meier estimation method and were compared by with the logrank test. For multivariable analysis for cardiovascular events, the proportional hazard assumption was tested with Schoenfeld residuals and the Supremum test for proportional hazards assumption. Possible predictors were tested by using Cox proportional hazard regression with the bootstrapping method. Each proportional hazards model was subjected to 1000 bootstrap replications by using random samples generated from and consisting of the same number of patients as the original model. Bootstrap estimates of hazard ratios and $95 \%$ confidence intervals were calculated by using a bias-corrected method derived from the 1000 replications. All statistical analyses were performed with the Statistical Analysis Software package (SAS version 9.1, SAS Institute, Inc, Cary, NC).

\section{RESULTS \\ Patient Characteristics}

Clinical and echocardiographic characteristics of the 210 patients are summarized in Table 1 . The ethnicity of all the patients was Korean. Severe dyspnea with New York Heart Association functional class 3 or 4 was present in $22 \%$ of the patients before AVR. LVEF was less than $50 \%$ in $18 \%$ of the patients. The mean $\mathrm{E} / \mathrm{E}^{\prime}$ value was increased at $16.8 \pm 8.6$, and the LV mass index was increased at $151 \mathrm{~g} /$ $\mathrm{m}^{2}$. E/E' $\mathrm{E}^{\prime}$ values were correlated with $\operatorname{LVEF}(r=-0.34$, $P<.001)$, aortic valve area $(r=-0.24, P=.001), \mathrm{LV}$ mass index $(r=0.23, P<.001)$, LA volume index $(r=0.42, P<.001)$, pulmonary hypertension $(r=0.48$, $P<.001)$, and the functional class of the patients $(r=0.30$, $P<.001)$. A history of coronary artery disease was presented in $17 \%$ of the patients, and coronary artery bypass grafting during AVR was performed in $11 \%$ of the patients.

\section{Postoperative Hospital Course}

None of the patients experienced early postoperative death within 30 days after AVR. Postoperative ventilator time was $11.0 \pm 8.3$ hours. Mean postoperative intensive cardiac unit and hospital stays after valve surgery were $1.0 \pm 1.0$ days and $8.0 \pm 3.0$ days, respectively.

Postoperative surgical complications were present in 5 $(2.3 \%)$ patients, and in-hospital cardiovascular complications were present in $13(6.2 \%)$ patients (embolic cerebral 
TABLE 1. Characteristics of the study population

\begin{tabular}{|c|c|}
\hline & Values $(n=210)$ \\
\hline Age, y & $64.6 \pm 10.0$ \\
\hline Male sex, n $(\%)$ & $136(64.8)$ \\
\hline Body surface area, $\mathrm{m}^{2}$ & $1.7 \pm 0.2$ \\
\hline NYHA functional class & $2.1 \pm 0.7$ \\
\hline NYHA class III or IV, n (\%) & $46(21.9)$ \\
\hline Hypertension, n (\%) & $92(43.8)$ \\
\hline Diabetes mellitus, n (\%) & $36(17.1)$ \\
\hline Smoking, n $(\%)$ & $79(37.6)$ \\
\hline History of CAD, n (\%) & $36(17.1)$ \\
\hline End-systolic dimension, $\mathrm{mm}$ & $33.9 \pm 8.6$ \\
\hline End-diastolic dimension, $\mathrm{mm}$ & $54.0 \pm 7.4$ \\
\hline Left ventricular ejection fraction $(\%)$ & $60.4 \pm 11.7$ \\
\hline $\begin{array}{l}\text { Left ventricular ejection } \\
\text { fraction }<50 \%, \mathrm{n}(\%)\end{array}$ & $37(17.6)$ \\
\hline Left ventricular mass index, $\mathrm{g} / \mathrm{m}^{2}$ & $151.4 \pm 43.0$ \\
\hline LA volume index, $\mathrm{mL} / \mathrm{m}^{2}$ & $38.6 \pm 14.6$ \\
\hline $\mathrm{E} / \mathrm{E}^{\prime}$ & $16.8 \pm 8.6$ \\
\hline $\begin{array}{l}\text { Peak systolic pulmonary artery } \\
\text { pressure, } \mathrm{mm} \mathrm{Hg} *\end{array}$ & $39.6 \pm 11.4$ \\
\hline \multicolumn{2}{|l|}{ Valve morphology } \\
\hline Tricuspid/bicuspid/unicuspid & $69(32.9) / 141(67.1) / 0(0)$ \\
\hline Aortic valve area, $\mathrm{cm}^{2}$ & $0.71 \pm 0.16$ \\
\hline Mean transvalvular gradient, $\mathrm{mm} \mathrm{Hg}$ & $57.1 \pm 17.0$ \\
\hline \multicolumn{2}{|l|}{ Aortic prosthesis type, n (\%) } \\
\hline Mechanical & $71(33.8)$ \\
\hline Bioprosthesis & $139(66.2)$ \\
\hline Aortic prosthetic size, $\mathrm{mm}$ & $22.3 \pm 1.8$ \\
\hline $\begin{array}{l}\text { Associated coronary artery } \\
\text { bypass graft, } \mathrm{n}(\%)\end{array}$ & $22(10.5)$ \\
\hline \multicolumn{2}{|l|}{ Preoperative medication, $\mathrm{n}(\%)$} \\
\hline Statin & $82(39.0)$ \\
\hline ACE inhibitor or ARB & $70(33.3)$ \\
\hline$\beta$-Blocker & $60(28.6)$ \\
\hline Calcium-channel blocker & $43(20.5)$ \\
\hline
\end{tabular}

$N Y H A$, New York Heart Association; $C A D$, coronary artery disease; $L A$, left atrial; $E /$ $E e$, ratio between early diastolic mitral inflow and mitral annular velocity; $A C E$, angiotensin-converting enzyme; $A R B$, angiotensin receptor blocker. *Peak systolic pulmonary arterial pressure was available only in 163 patients because reliable tracing of tricuspid regurgitation Doppler scanning was impossible.

infarction in 2, transient ischemic accident in 1, intraoperative intra-arterial balloon pump in 1 , cardiopulmonary resuscitation or cardioversion caused by clinically significant arrhythmia resulting in sudden collapse in 7 , pacemaker insertion during surgical intervention caused by atrioventricular block in 1, and pericardiocentesis caused by pericardial effusion in 1). Cardiovascular complications were more prevalent in patients with preoperative $\mathrm{E} / \mathrm{E}^{\prime}$ values of greater than 12 (Figure 1).

\section{Midterm Morbidity and Mortality}

All-cause mortality was confirmed in the entire study population as follows. Telephone or outpatient interviews were performed with $97.1 \%(n=204)$ of the patients or their firstdegree relatives to confirm the mortality and morbidity of the

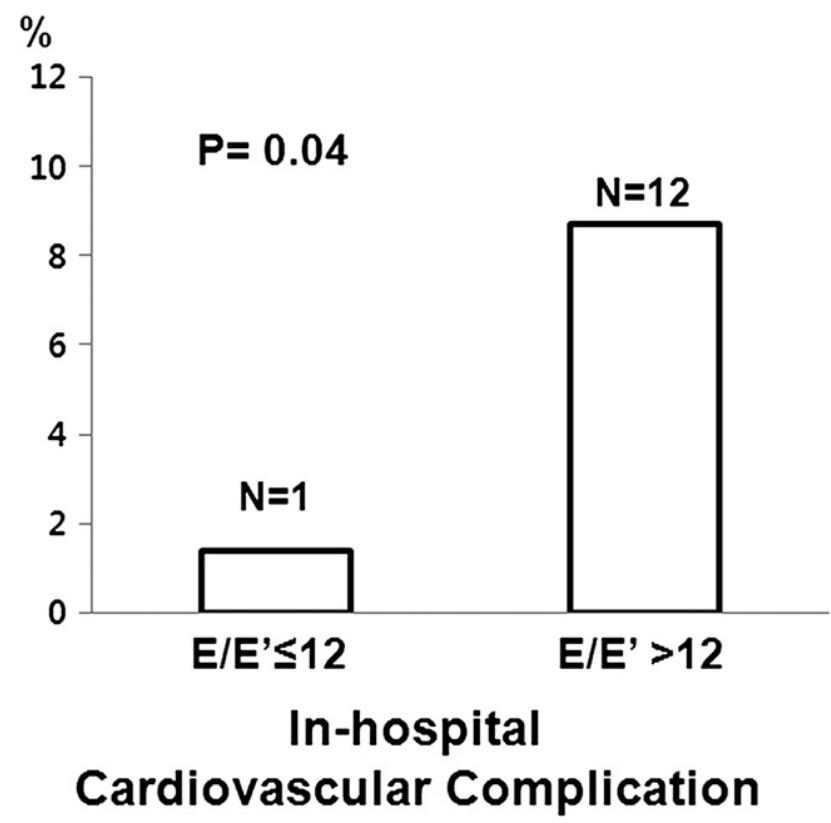

FIGURE 1. In-hospital cardiovascular complications according to the ratio between early diastolic mitral inflow and mitral annular velocity $\left(E / E^{\prime}\right)$. Postoperative cardiovascular complications, including embolic cerebral infarction, cardiopulmonary resuscitation, and arrhythmia requiring cardioversion or pacemaker insertion, occurred in patients with $\mathrm{E} / \mathrm{E}^{\prime}$ values of greater than $12(P<.05)$, suggesting increased left ventricular filling pressure before surgical intervention.

patients. The mortality of the rest of the patients $(2.9 \%$, $\mathrm{n}=6$ ), who could not be reached by telephone, was confirmed by using national registry of death and survival data.

The median follow-up duration was $25.39 \pm 16.2$ months. Four $(1.8 \%)$ patients died during follow-up (Figure 2). Among them, cardiovascular mortality occurred in 2 patients. Cardiovascular events were more prevalent in the patients with high $\mathrm{E} / \mathrm{E}^{\prime}$ values in the overall study population (Figure 3, A). Fourteen $(10.1 \%)$ of the patients with $\mathrm{E} / \mathrm{E}^{\prime}$ values of greater than $12(\mathrm{n}=72)$ had morbidity of cardiovascular events, but only $2(2.8 \%)$ of the patients with $\mathrm{E} / \mathrm{E}^{\prime}$ values of 12 or less $(n=138)$ had cardiovascular events during the follow-up period $(P=.03$; Figure $3, A)$. This finding persisted among the patients with preserved LVEF (LVEF $>50 \%, P=.04$; Figure 3, B). Multivariable analysis using Cox proportional hazard regression with the bootstrapping method also showed a significantly high hazard ratio with increased $\mathrm{E} / \mathrm{E}^{\prime}$ values of greater than 12 (Table 2).

\section{DISCUSSION}

In this study postoperative outcome of isolated AVR because of severe AS was excellent, with a very low mortality rate. Average preoperatively estimated LV filling pressure, as determined by means of Doppler echocardiographic analysis, was increased in patients with severe AS. Midterm mortality was excellent, but postoperative cardiovascular 


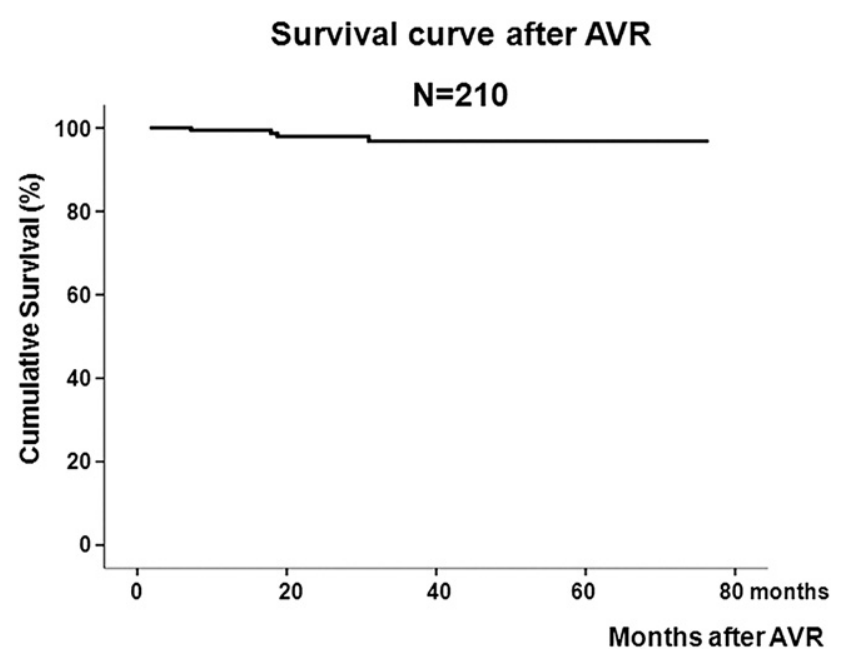

FIGURE 2. Survival curve after aortic valve replacement ( $A V R)$. The Kaplan-Meier survival curve shows excellent postoperative outcome with very low midterm mortality (median follow-up duration, $25.39 \pm 16.2$ months). Only 4 (1.8\%) patients died during follow-up.

events were more common in the patients with increased preoperative $L V$ filling pressures $\left(E / E^{\prime}>12\right)$. On the other hand, early postoperative outcomes were not related to the preoperative aortic valve gradients or area.

\section{Outcome of Isolated AVR in Patients With Degenerative AS}

Early postoperative mortality has decreased ${ }^{14}$ with improvement in surgical techniques and perioperative care. In-hospital mortality of isolated AVR varies according to the study group, but it is usually less than $5 \%,{ }^{15-17}$ and midterm mortality has been reported to be less than $10 \% .{ }^{18}$ In our clinical experience there was no in-hospital mortality, and the midterm mortality was only $3 \%$ of overall patients. Our excellent postoperative outcome can be explained by the characteristics of our study population, all of whom are Korean. Our study population is younger, and the percentage of bicuspid aortic valve was higher than in other previous studies, ${ }^{3}$ which were mainly reported from Western countries. Moreover, the prevalence of coronary artery disease is much lower than that of other previous studies ${ }^{16,18}$ because of less prevalent atherosclerosis in the Asian population. ${ }^{19}$

\section{Preoperative LV Filling Pressure as a Risk for Postoperative Outcomes}

LVEF and cardiac symptoms have been used to determine the timing of valvular surgery, especially in patients with $\mathrm{AS}^{20}$ This guideline is easy to use and supported by much clinical data. ${ }^{21,22}$ Still, there are debates on the right timing of AVR. Even though the presence of symptoms is a definite predictor of poor outcome, ${ }^{23}$ patients might not be aware of the fact that they are limited clinically, and fur-

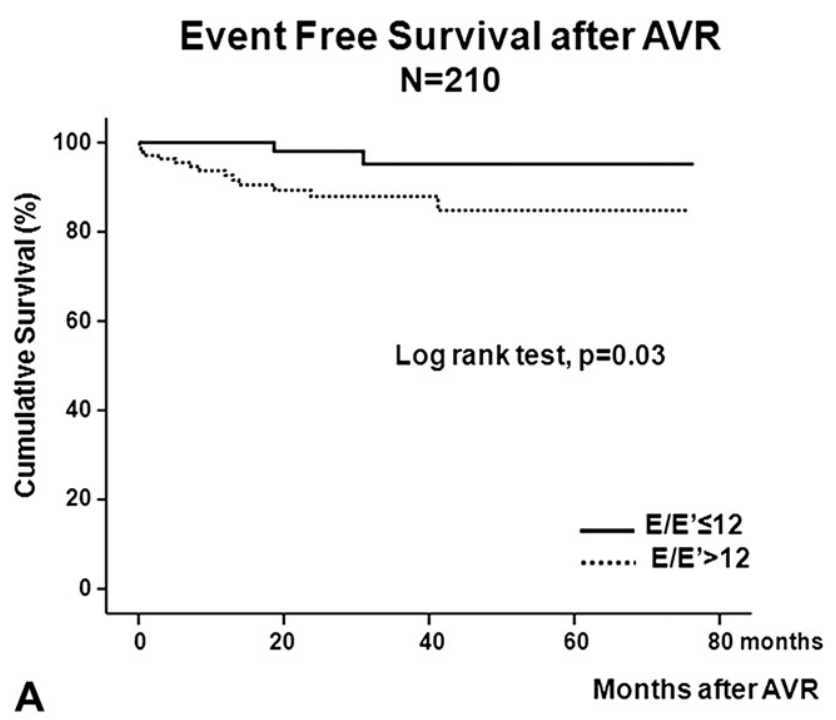

\section{Event Free Survival after AVR LVEF $>50 \%(n=173)$}

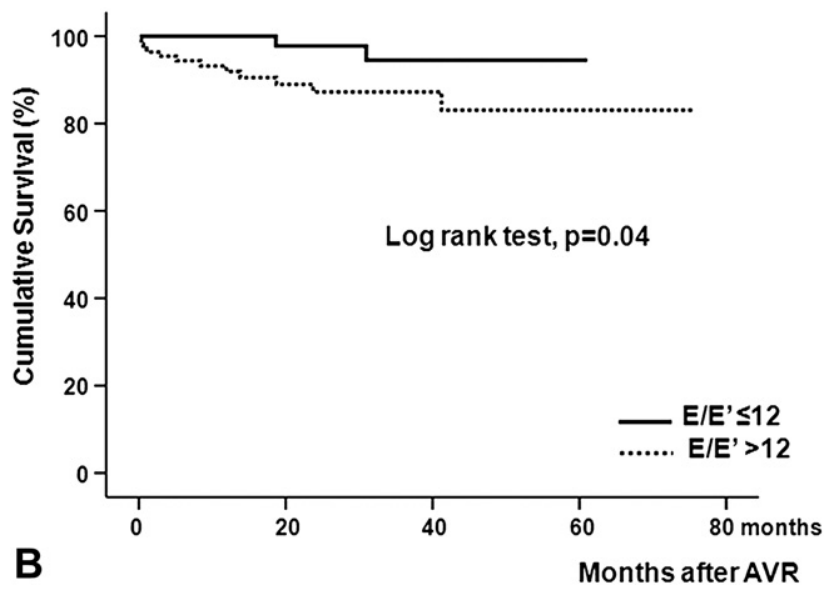

FIGURE 3. Event-free survival after aortic valve replacement (AVR). A, The cardiovascular event-free survival curve shows a significantly higher incidence of cardiovascular events with an increased ratio between early diastolic mitral inflow and mitral annular velocity $\left(\mathrm{E} / \mathrm{E}^{\prime}\right)$ values. B, Differences in event-free survival according to the estimated left ventricular filling pressure was also observed in the patients with preserved left ventricular ejection fractions.

thermore, symptoms are not specific. Moreover, symptoms are sometimes insidious and are not easily elicited by physicians. We might need to perform exercise testing to assess the patient's functional status. ${ }^{24}$ Even when AVR is performed according to the guidelines, persistent or recurrent heart failure can be observed after successful AVR, and persistent heart failure has been reported to be present in $10 \%$ of patients 5 years after AVR. ${ }^{4}$ Therefore we need more objective parameters to discriminate the high-risk patients who are at risk of postoperative heart failure.

Increased LV filling pressure is a common pathophysiology of pulmonary congestion in patients with heart failure, ${ }^{5}$ 
TABLE 2. Preoperative risk factors for postoperative cardiovascular events

\begin{tabular}{lccc}
\hline \multicolumn{1}{c}{ Variables } & Hazard ratio & $\mathbf{9 5} \% \mathbf{C I}$ & $\boldsymbol{P}$ value \\
\hline Age, y & 1.0 & $0.96-1.07$ & .63 \\
Aortic valve area, $\mathrm{cm}^{2}$ & 17.0 & $0.96-300.2$ & .06 \\
$\mathrm{LV}$ ejection fraction, \% & 1.0 & $0.94-1.08$ & .53 \\
$\mathrm{LV}$ mass index, $\mathrm{g} / \mathrm{m}^{2}$ & 1.0 & $0.98-1.00$ & .11 \\
E/E' $\mathrm{E}^{\prime}>12$ & 40.8 & $39.00-41.68$ & $<.001$ \\
\hline
\end{tabular}

$C I$, Confidence interval; $L V$, left ventricle; $E / E t$, ratio between early diastolic mitral inflow and mitral annular velocity.

including patients with $\mathrm{AS} .^{2}$ Increased LV filling pressure has been shown to be positively correlated with the functional class of the patients and the development of pulmonary hypertension, ${ }^{2}$ which was also demonstrated in our study population. A prolonged increase in LV filling pressure promotes LA remodeling, ${ }^{25}$ which can be a substrate of atrial fibrillation and a source of embolism. ${ }^{26}$ Furthermore, myocardial fibrosis is an important pathology of the myocardium with diastolic dysfunction and LV filling pressure, and it can be a substrate for ventricular arrhythmia or conduction abnormality. In our study subjects fatal arrhythmias were more common in the patients with increased preoperative LV filling pressure, which can be associated with increased $\mathrm{LV}$ fibrosis and LA remodeling. The fact that $\mathrm{E} / \mathrm{E}^{\prime}$ values were not well correlated with the severity of AS using aortic valve pressure gradient and aortic valve area suggests that the increased preoperative LV filling pressure in patients with severe AS is not all from AS but also from independent, superimposed diastolic dysfunction. Increased LV filling pressure has been predictive of poor long-term outcome in patients with other conditions, such as diastolic heart failure, systolic heart failure, and acute myocardial infarction. ${ }^{27}$ In our study population cardiovascular events, including arrhythmia requiring resuscitation and embolic cerebral infarction, were more common in the patients with preoperatively increased LV filling pressure. After discharge, recurrent heart failure was more common in patients with preoperatively increased LV filling pressure. This phenomenon was also found in patients with preserved LVEF before AVR.

From our results, preoperative LV filling pressure did not affect the mortality of the patients undergoing isolated AVR but was associated with postoperative hospital course and postoperative morbidity. We also suggest that noninvasive measurements of LV filling pressure preoperatively can be a prognostic indicator of midterm cardiovascular events after isolated AVR in patients with severe AS, even in the setting of preserved LVEF. Postoperative $\mathrm{E} / \mathrm{E}^{\prime}$ values would be beneficial also for follow-up of longer-term outcome of the patients after AVR, which requires further study. The usefulness of LV filling pressure to determine the timing of the AVR in asymptomatic patients with severe AS is beyond our scope, but from our results, LV filling pressure deserves a serious consideration as a marker to identify the high-risk group in future clinical investigations of valvular heart diseases.

\section{Study Limitations}

Our study has several limitations. First, the preoperative and perioperative characteristics of our study population were collected in a retrospective manner, but our echocardiographic performance has been standardized since 2003 and recorded in an electronic database, which minimizes possible errors in data collection.

Second, our study population, all of whom are Korean, has relatively low risk compared with those of other previous studies from Western countries ${ }^{28}$; our data were not powered to address any association with mortality, and the effect of LV filling pressure on morbidity after AVR might not be generalized. However, the predictive value of $\mathrm{E} / \mathrm{E}^{\prime}$ has been validated in other conditions in other ethnic populations.

Third, LV filling pressure was not acquired by means of invasive cardiac catheterization but assumed based on $\mathrm{E} / \mathrm{E}^{\prime}$ values by using echocardiographic analysis. $\mathrm{E} / \mathrm{E}^{\prime}$ values can be influenced by LA pressure ${ }^{29}$ or LV systolic and diastolic pressure $^{30,31}$ and thus have the possibility of being confounded. However, LV filling pressure in patients with AS has been reported to be well correlated with LV filling pressure measured by means of invasive methods. ${ }^{10,32}$ Moreover, although cardiac catheterization is relatively safe, it remains an invasive procedure and is associated with measurable risk. In this context noninvasive measurement of LV filling pressure might be a safer method in routine clinical practice.

\section{CONCLUSIONS}

The incidence of early postoperative and midterm mortality after isolated AVR caused by severe AS is relatively low in the current era. Still, increased LV filling pressure measured by using echocardiographic analysis is associated with increased preoperative symptoms and early postoperative morbidity in patients with severe AS. Increased LV filling pressure did not increase mortality after AVR but was associated with midterm cardiovascular events. The aortic valve gradient and area were not related to the preoperative symptoms and postoperative clinical outcomes in patients with severe AS.

Multivariable analysis with the bootstrap method was technically supported by the biostatistics team, Samsung Biomedical Research Institute, Korea.

\section{References}

1. Murakami T, Hess OM, Gage JE, Grimm J, Krayenbuehl HP. Diastolic filling dynamics in patients with aortic stenosis. Circulation. 1986;73:1162-74.

2. Casaclang-Verzosa G, Nkomo VT, Sarano ME, Malouf JF, Miller FA Jr, Oh JK. $\mathrm{E} / \mathrm{Ea}$ is the major determinant of pulmonary artery pressure in moderate to severe aortic stenosis. J Am Soc Echocardiogr. 2008;21:824-7. 
3. Mihaljevic T, Nowicki ER, Rajeswaran J, Blackstone EH, Lagazzi L, Thomas J, et al. Survival after valve replacement for aortic stenosis: implications for decision making. J Thorac Cardiovasc Surg. 2008;135:1270-9.

4. Ruel M, Rubens FD, Masters RG, Pipe AL, Bedard P, Hendry PJ, et al. Late incidence and predictors of persistent or recurrent heart failure in patients with aortic prosthetic valves. J Thorac Cardiovasc Surg. 2004;127:149-59.

5. Zile MR, Brutsaert DL. New concepts in diastolic dysfunction and diastolic heart failure: part I: diagnosis, prognosis, and measurements of diastolic function. Circulation. 2002;105:1387-93.

6. Gjertsson P, Caidahl K, Farasati M, Oden A, Bech-Hanssen O. Preoperative moderate to severe diastolic dysfunction: a novel Doppler echocardiographic longterm prognostic factor in patients with severe aortic stenosis. J Thorac Cardiovasc Surg. 2005;129:890-6.

7. Malouf JF, Enriquez-Sarano M, Pellikka PA, Oh JK, Bailey KR, Chandrasekaran K, et al. Severe pulmonary hypertension in patients with severe aortic valve stenosis: clinical profile and prognostic implications. J Am Coll Cardiol. 2002;40:789-95.

8. Nagueh SF, Middleton KJ, Kopelen HA, Zoghbi WA, Quinones MA. Doppler tissue imaging: a noninvasive technique for evaluation of left ventricular relaxation and estimation of filling pressures. J Am Coll Cardiol. 1997;30: 1527-33.

9. Ommen SR, Nishimura RA, Appleton CP, Miller FA, Oh JK, Redfield MM, et al. Clinical utility of Doppler echocardiography and tissue Doppler imaging in the estimation of left ventricular filling pressures: a comparative simultaneous Doppler-catheterization study. Circulation. 2000;102:1788-94.

10. Dalsgaard M, Kjaergaard J, Pecini R, Iversen KK, Kober L, Moller JE, et al. Left ventricular filling pressure estimation at rest and during exercise in patients with severe aortic valve stenosis: comparison of echocardiographic and invasive measurements. J Am Soc Echocardiogr. 2009;22:343-9.

11. Devereux RB, Alonso DR, Lutas EM, Gottlieb GJ, Campo E, Sachs I, et al. Echocardiographic assessment of left ventricular hypertrophy: comparison to necropsy findings. Am J Cardiol. 1986;57:450-8.

12. Ujino K, Barnes ME, Cha SS, Langins AP, Bailey KR, Seward JB, et al. Twodimensional echocardiographic methods for assessment of left atrial volume. Am J Cardiol. 2006;98:1185-8.

13. Stamm RB, Martin RP. Quantification of pressure gradients across stenotic valves by Doppler ultrasound. J Am Coll Cardiol. 1983;2:707-18.

14. Levy F, Laurent M, Monin JL, Maillet JM, Pasquet A, Le Tourneau T, et al. Aortic valve replacement for low-flow/low-gradient aortic stenosis operative risk stratification and long-term outcome: a European multicenter study. $J$ Am Coll Cardiol. 2008;51:1466-72.

15. Rabus MB, Kirali K, Kayalar N, Mataraci I, Yanartas M, Ulusoy-Bozbuga N, et al. Effects of patient-prosthesis mismatch on postoperative early mortality in isolated aortic stenosis. J Heart Valve Dis. 2009;18:18-27.

16. Blais C, Dumesnil JG, Baillot R, Simard S, Doyle D, Pibarot P. Impact of valve prosthesis-patient mismatch on short-term mortality after aortic valve replacement. Circulation. 2003;108:983-8.

17. Brown ML, Pellikka PA, Schaff HV, Scott CG, Mullany CJ, Sundt TM, et al. The benefits of early valve replacement in asymptomatic patients with severe aortic stenosis. J Thorac Cardiovasc Surg. 2008;135:308-15.
18. Tasca G, Mhagna Z, Perotti S, Centurini PB, Sabatini T, Amaducci A, et al. Impact of prosthesis-patient mismatch on cardiac events and midterm mortality after aortic valve replacement in patients with pure aortic stenosis. Circulation. 2006; 113:570-6.

19. Budoff MJ, Nasir K, Mao S, Tseng PH, Chau A, Liu ST, et al. Ethnic differences of the presence and severity of coronary atherosclerosis. Atherosclerosis. 2006; 187:343-50.

20. Bonow RO, Carabello BA, Chatterjee K, de Leon AC Jr, Faxon DP, Freed MD, et al. 2008 Focused update incorporated into the ACC/AHA 2006 guidelines for the management of patients with valvular heart disease: a report of the American College of Cardiology/American Heart Association Task Force on Practice Guidelines (Writing Committee to Revise the 1998 Guidelines for the Management of Patients With Valvular Heart Disease): endorsed by the Society of Cardiovascular Anesthesiologists, Society for Cardiovascular Angiography and Interventions, and Society of Thoracic Surgeons. Circulation. 2008;118: e523-661.

21. Lund O. Preoperative risk evaluation and stratification of long-term survival after valve replacement for aortic stenosis. Reasons for earlier operative intervention. Circulation. 1990;82:124-39.

22. Kvidal P, Bergstrom R, Horte LG, Stahle E. Observed and relative survival after aortic valve replacement. J Am Coll Cardiol. 2000;35:747-56.

23. Ross J Jr, Braunwald E. Aortic stenosis. Circulation. 1968;38:61-7.

24. Otto CM, Burwash IG, Legget ME, Munt BI, Fujioka M, Healy NL, et al. Prospective study of asymptomatic valvular aortic stenosis. Clinical, echocardiographic, and exercise predictors of outcome. Circulation. 1997;95:2262-70.

25. Tsang TS, Barnes ME, Gersh BJ, Bailey KR, Seward JB. Left atrial volume as a morphophysiologic expression of left ventricular diastolic dysfunction and relation to cardiovascular risk burden. Am J Cardiol. 2002;90:1284-9.

26. Cabin HS, Clubb KS, Hall C, Perlmutter RA, Feinstein AR. Risk for systemic embolization of atrial fibrillation without mitral stenosis. Am J Cardiol. 1990;65: 1112-6.

27. Yu CM, Sanderson JE, Marwick TH, Oh JK. Tissue Doppler imaging a new prognosticator for cardiovascular diseases. J Am Coll Cardiol. 2007;49: 1903-14.

28. Kim YS, Choi JO, Hwang ES, Lee MM, Chae IH, Kim CH, Sohn DW, et al. The incidence of coronary artery stenosis in patients with valvular heart disease. Korean Circ J. 2001;31:1141-9.

29. Ishida Y, Meisner JS, Tsujioka K, Gallo JI, Yoran C, Frater RW, et al. Left ventricular filling dynamics: influence of left ventricular relaxation and left atrial pressure. Circulation. 1986;74:187-96.

30. Choong CY, Abascal VM, Thomas JD, Guerrero JL, McGlew S, Weyman AE. Combined influence of ventricular loading and relaxation on the transmitral flow velocity profile in dogs measured by Doppler echocardiography. Circulation. 1988;78:672-83.

31. Thomas JD, Choong CY, Flachskampf FA, Weyman AE. Analysis of the early transmitral Doppler velocity curve: effect of primary physiologic changes and compensatory preload adjustment. J Am Coll Cardiol. 1990;16:644-55.

32. Bruch C, Stypmann J, Grude M, Gradaus R, Breithardt G, Wichter T. Tissue Doppler imaging in patients with moderate to severe aortic valve stenosis: clinical usefulness and diagnostic accuracy. Am Heart J. 2004;148:696-702. 